\title{
FOUR score versus GCS in patients with traumatic brain injury in the prehospital setting
}

\author{
Matej Rubelli Furman ( $\nabla$ matej.rubelli.furman@siol.net ) \\ Zdravstveni dom Koper https://orcid.org/0000-0003-0413-0606 \\ Mario Gorenjak \\ Univerza v Mariboru Medicinska fakulteta \\ Janez Ravnik \\ Univerzitetni Klinicni Center Maribor
}

\section{Research article}

Keywords: traumatic brain injury, coma, GCS (Glasgow Coma Scale), FOUR (Full Outline of UnResponsiveness) score, outcome

Posted Date: November 25th, 2020

DOl: https://doi.org/10.21203/rs.3.rs-18036/v4

License: (c) (i) This work is licensed under a Creative Commons Attribution 4.0 International License. Read Full License 


\section{Abstract}

Background: In the last few decades, different coma scoring scales have been proposed. The purpose of this study is to compare two coma scales, the GCS (Glasgow Coma Scale) and the FOUR score (Full Outline of UnResponsiveness score), aiming to examine which scale is better for predicting outcome in traumatic brain injury (TBI) patients in the prehospital setting.

Methods: We evaluated the GCS and FOUR scores in the prehospital setting at three different prehospital timepoints, and we reassessed the scores in surviving patients 24 hours, one month and three months after the injury. Then, we compared the outcomes.

We used the $\chi^{2}$ method, and based on the analysis with the best cut-off point for each model, we calculated the sensitivity, specificity and correct prediction of outcomes with four severity scores. The Youden index, Z score, McNemar's test and ROC curve were also assessed. $\mathrm{P}<0.05$ was considered statistically significant. Both scales were ranked with gain ratios.

Results: We included 200 TBI patients who were treated in a prehospital setting by a prehospital specialized medical unit. In terms of the predictions of positive outcomes, our study showed the following:

1. Twenty-four hours after the injury, the best cut-off points obtained were from the FOUR 1 and GCS 1 models.

2. One month after the injury, the best cut-off points obtained were from the following models: FOUR 2 and GCS 3 as well as FOUR 3 and GCS 3.

3. Three months after the injury, the best cut-off points obtained were from the following models: FOUR 2 and GCS 1, FOUR 3 and GCS 1 , and GCS 1 and GCS 2.

Conclusions: In our study, the results of our research confirm that there are no practical or clinical differences between the GCS and FOUR scores in terms of predicting morality outcomes 24 hours, one month, and three months after injury. No statistically significant differences were found in the Youden index or the area under the ROC curve 24 hours, one month or three months after the injury.

\section{Background}

The assessment of the depth of consciousness in patients with brain injuries is particularly important and demanding in emergency scenarios outside the hospital. In the last few decades, several different coma score scales have been proposed. In 1974, a new scale, the Glasgow Coma Scale (GCS), was introduced; since then, it has been widely used and is still largely used worldwide [1]. The GCS offers a good tool for assessing the depth of consciousness and coma. Many studies have suggested that this scale should be used with other neurological assessments [2-5] and should be administered as soon as possible in emergency situations. The GCS may be repeated at intervals, especially when neurological function fluctuates [6]. The purpose of the GCS is to evaluate patients with TBI and predict their chances of neurological recovery. The GCS presents several weaknesses, such as limited utility in intubated patients as well as an inability to estimate brainstem reflexes. Considering these limitations, a new coma score, the Full Outline of UnResponsiveness (FOUR) score, has been developed [7] to overcome these shortcomings and to provide further neurological details that might lead to a better prediction of outcomes in coma patients.

The FOUR score has four components: eye responses, motor responses, brainstem reflexes, and respiration patterns. Each component ranges from a minimal value of 0 to a maximal value of 4 [7]. The total FOUR score ranges from a minimum of 0 to a maximum of 16 [9]. The components are described in Table 1.

\section{Methods}


The present study was approved by the National Medical Ethics Committee of the Republic of Slovenia. All declarations were performed in accordance with the relevant guidelines and regulations. We performed a prospective observational cohort study over a one-and-a-half-year period from March 2012 to September 2013.

We contacted prehospital units in large community areas in Slovenia. We sent an introduction letter to colleagues describing the aim and procedures of the study. Recruitment materials include accurate description of the research purpose, name and address of the investigator, condition under study, plans of the study and investigator checklist, eligibility criteria of the patients, time commitments required, location of the research, written and illustrated material on GCS and FOUR score with links to web access for further explanations (official and dedicated web sites, videos...), sample excel tables of study data, medical ethics consent, informed consent, person to contact for further information. We also sent reminder letters to increase the response rate among clinicians. We used email and SMS on scheduled time to colleagues to re-evaluate patient outcomes.

Our inclusion criteria were minor or moderate-to-severe TBI patients with altered mental status and/or coma who were either polytraumatized or had isolated head injuries. We did not include patients under the age of 18, patients who required CPR or patients who died before arriving at the hospital.

TBI patients were treated and evaluated by emergency prehospital medical unit personnel. The arrival time to the nearest regional hospital was up to 15 minutes. All patients were treated according to the ATLS guidelines.

We evaluated the GCS and FOUR scores in the prehospital setting at three different time points: immediately upon first contact with the patient at the scene, after management of the patient by the prehospital medical unit, and during patient handover by the ambulance staff at the hospital (Table 2). Outcomes were assessed after 24 hours, 1 month and 3 months.

We included 200 patients with TBI in our study (133 men and 67 women). The study size was obtained with a power analysis using GPower 3.1.9 software and $z$ test for an a priori power calculation using alpha (a) of 0.05 , power of $80 \%$ and effect size (d) of 0.8 calculated separately for FOUR and GCS scores. A priori power analysis has shown that for $80 \%$ power, at least 107 vs. 15 or 27 vs. 27 individuals have to be included for allocation ratios of 0.14 or 1 , respectively. Post hoc statistical power of proportions is presented as sensitivity $(1-\beta)$.

An overview of the clinical characteristics of the cohort study is shown in Table 3.

The sensitivity, specificity, correct prediction and Youden's J-statistic (index) [13] were obtained with a two-by-two table. Youden's J-statistic was used to assess the performance of a dichotomous diagnostic test. For each scale and each outcome, all possible cut-off points were constructed by means of two-by-two tables. We calculated the sensitivity (true positive) by choosing survivors with equal or more points according to the selected cut-off point. In addition, we calculated the specificity (true negative), where we chose nonsurvivors_with fewer points according to the selected cut-off point. The best cut-off points for each of the outcomes were further assessed and pairwise compared. The percentages of correct predictions of outcomes were obtained according to these cut-off points. For each score, receiver operating characteristic (ROC) curves were obtained [14-17]. The greater the area under the ROC curve was, the better the scoring system. Data were analysed with IBM SPSS Statistics for Windows, version 21.0. Armonk, NY: IBM Corp. The outcome prediction data were compared to the observed data using McNemar's test for comparison of paired dichotomous categorical mutually exclusive variables to meet the assumptions. The comparisons of the areas under the ROC curves and the analyses of the differences in the Youden index were performed using the method described by Hanley and McNeil [14-17]. $\mathrm{P}<0.05$ was considered statistically significant.

Possible biases that could affect our study:

- In relation to data collection, we spot a potential bias about doctors who may superficially perform GCS and FOUR scores because of a lack of skills, especially for FOUR scores. We skip that potential unfamiliarity, educating clinicians who performed and interpreted the scores, exposing them to the same level of basic knowledge. 
- We also detected a possible bias evaluating GCS and FOUR scores in intubated and mechanically ventilated patients compared to patients who breathed spontaneously. In this study, the number of intubated and mechanically ventilated patients in the prehospital arena was insufficient to statistically influence the $p$ value of the suggested models in our study.

\section{Results}

Within 24 hours after the injury, 6 patients (3\%) died. One month after the injury, we registered 23 deceased patients (11,5\%), and three months after the injury, we recorded a cumulative total of 25 deceased patients $(12.5 \%$ of the total number of studied patients). Upon first contact at the scene, we assessed the FOUR 1 score and the GCS 1 score. The average score upon first contact at the scene for the FOUR 1 model was 14/16 and for the GCS 1 model was 12.6/15. The prehospital medical unit performed head-to-toe immobilization and fixation and placed an IV line with IV therapy; additional oxygen was administered. Among all patients, 33 out of 200 (16,5\%) were ET intubated (with appropriate sedation, analgesia and muscular relaxation), mechanically ventilated and monitored with end-tidal $\mathrm{CO}_{2}$. No missing data were present in the final dataset.

Table 3 shows an overview of the clinical characteristics of the study cohort and present data obtained from the assessment of the two singular components present in both scales: the eye and motor response for the GCS and FOUR scores. Both the eye and motor responses of the two scales were compared to the severity of TBI (mild, moderate, severe and other). We additionally performed possible outcomes after brain injury using the Glasgow Outcome Scale Extended (GOS-E) with the following outcome ranges: eight progressive steps from 8 and 7 for good recovery, 6 and 5 for moderate recovery, 4 and 3 for severe disability, 2 for persistent vegetative state and 1 for death.

The best cut-off points for predicting outcomes within 24 hours after the injury were 12 for the FOUR 1 model and 8 for the GCS 1 model, evaluated immediately upon first contact at the scene (1: first assessment). Table 4 provides data regarding the sensitivity, specificity and correct predictions of outcome 24 hours after the injury for the best cut-off points for the Youden index. We observed no statistically significant differences within 24 hours after the injury between the FOUR score and the GCS for assessments 2 and 3 (2: after initial management and intervention of the patient, 3: during patient handover by the ambulance staff at the hospital).

These results, according to McNemar's test, confirmed that the FOUR 1 model and the GCS 1 model showed slightly better predictive power in terms of patient outcome $(p=0,031)$ (Table 4). The best cut-off values for the Youden index after 24 hours were 0.85 for the FOUR 1 model and 0.88 for the GCS 1 model (Table 4). The area under the ROC curve (area \pm standard error) obtained after 24 hours was $0.94 \pm 0.02$ for FOUR 1 and was almost the same at $0.93 \pm 0.02$ for GCS 1 (Table 4). We conclude that no differences in the Youden index or area under the ROC curve 24 hours after the injury were found.

In addition to the 24-hour follow-up outcomes, we also evaluated the GCS and FOUR scores in surviving patients one and three months after the injury.

The two scores were also compared by drawing ROC curves to avoid bias of arbitrary cut-off points. The comparison of the GCS score and the FOUR score in patients who survived for 24 hours (A) and for one (B) and three months (C) after the injury in regard to outcomes showed only a minimal significant difference in the correct prediction of outcomes in surviving patients 24 hours after the injury (Figure 1).

Analysis performed one month after the injury showed that the best cut-off point was 8 for the FOUR 2 and FOUR 3 models and 11 for the GCS 3 model (Table 5). According to McNemar's test, these two pairs of models (each model $p=0,021)$ had the highest outcome prediction value among all combined models. The cut-off value for the Youden index was the same at 0.81 for the FOUR 2, FOUR 3 and GCS 3 models (Table 5). The ROC curve was the same at $0.91 \pm 0.04$ for both the FOUR 2 and FOUR 3 models and was $0.95 \pm 0.05$ for the GCS 3 model (Table 5). No differences in the Youden index or area under the ROC curve were found. 
Data obtained from the analysis performed three months after the injury showed that among all combined models and according to McNemar's test, the best three pair of models (each model $p=0,007$ ) were the FOUR 2 and FOUR 3 (both cut-off values of 12) as well as GCS 1 (cut-off value of 12) and GCS 2 (cut-off value of 9) models (Table 6). The Youden index values were 0.77 for the FOUR 2, FOUR 3 and CGS 2 models and 0.78 for the GCS 1 model (Table 6). The ROC was $0.89 \pm 0.04$ for the FOUR 2 and FOUR 3 models, $0.93 \pm 0.02$ for the GCS 1 model and $0.95 \pm 0.02$ for the GCS 2 model (Table 6). No significant differences in the Youden index or area under the ROC curve were found.

\section{Discussion}

Impaired consciousness is present in many injured patients. Efforts are directed to evaluate the depth of consciousness in these patients for proper management and prediction. The aim of the study was to compare the GCS and FOUR scores and to verify their ability to predict outcomes in TBI coma patients outside the hospital setting.

Since 1974 [1], when the GCS was introduced, the GCS has been widely used in the prehospital setting. In 2005, the FOUR score [7] was proposed to reduce some limitations of the GCS. Currently, the FOUR score is mostly employed in intensive and neurological care units.

The advantages of the FOUR score have been assessed by Wijdicks et al. [7], especially in neurologically critically ill patients who are intubated. When we compared the GCS and FOUR scores, we noticed a key difference: the verbal response is not an intrinsic part of the FOUR score. Taking this into consideration, the FOUR score is very useful in intubated patients [7]. Intubation is a common procedure after injury. The FOUR score tests essential brainstem reflexes and provides information about the degree of brainstem injury that is not registered with the GCS. The FOUR score can distinguish a locked-in syndrome and a possible vegetative state [7] and includes signs suggestive of uncal herniation [7]. The evaluation of respiratory patterns in the FOUR score may also add information about the presence of respiratory drive [7]. Studies have also shown that the in-hospital outcomes between the scales were better for the lowest total FOUR scores than for the GCS scores [7]. Conclusions obtained in previous studies have shown that the FOUR score is an accurate predictor of outcome in TBI patients [8], that it has some advantages over the GCS [8] and that it can be performed in a variety of ICU contexts [8]. The FOUR score is easily taught and simple to administer, and it provides essential neurologic information that allows for an accurate assessment of patients with altered consciousness with excellent interrater agreement among medical intensivists [9]. The FOUR score might be a better prognostic tool for ICU outcomes than the GCS, most likely because it integrates brainstem reflexes and respiration [10]. Other studies have shown the predictive value of the FOUR score on admission in patients after moderate and severe TBI [11]. These studies also showed that the predictive ability for the primary outcome 2 weeks after injury was no better than that with the GCS score [11]. For nontraumatic comatose patients, different parameters as predictors of outcome in the prehospital environment were also studied [12].

Analyses performed between the GCS and FOUR scores in the hospital environment have demonstrated that the GCS is missing the key essential elements of a comprehensive neurological examination for comatose patients [18]. In the same study, it was confirmed that the FOUR score maintained simplicity and, at the same time, provided far better information [18]. Other previous studies have demonstrated that the GCS and FOUR scores show comparable results in the assessment of patients with traumatic brain injury [19]. These data show that there are excellent statistical correlations between the two scoring systems [19]. Moreover, these studies show that the FOUR score provides better details regarding the neurological status of patients [19]. The results can be considered clinically relevant because of the strong statistical association obtained as well as the agreement in the literature [19]. Overall, there are currently multiple scores used to determine the prognosis of patients in intensive care units. However, a scoring system should be simple, reliable, and predictive of morbidity and outcome.

Due to the different categories of scores, the FOUR score is more effective in evaluating patients who are unconscious and dependent on mechanical ventilation. Prospective studies with larger cohorts of patients treated in various intensive care 
units for longer durations are needed to evaluate whether the application of these scales influences functional and cognitive outcomes [20].

In addition, further comparative neurological outcome studies also showed that the outcome of patients admitted to the ICU was significantly higher when the GCS or the FOUR score was used [21]. Discrimination was fair for both scores, but the FOUR score was superior to the GCS [21]. Calibration was better for the FOUR score than for the GCS in the ICU [21]. The sensitivity, specificity, positive predictive value, negative predictive value, and accuracy were also better for the FOUR score than for the GCS [21]. Good correlation was observed between the two scores [21].

A comprehensive overview of the relationship between a patient's FOUR score and outcome is still lacking. A recent study on the FOUR score showed that the FOUR score had a close overall relationship with in-hospital outcomes and poor functional outcomes in patients with impaired consciousness [22]. This research also claimed that there was insufficient evidence to determine whether performance was modified in different groups, and there was some suggestion that the assessment of brainstem reflexes and respiratory patterns made less of a contribution than eye and motor scores [22].

In the present study, our data showed no statistically significant difference in terms of the correct prediction of outcome 24 hours after the injury. We found no statistically significant differences in the Youden index or area under the ROC curve after 24 hours, no statistically significant differences one month after the injury, and no statistically significant differences three months after the injury.

In our opinion, we should obtain a better understanding of the anatomical and pathophysiological pathways that are not evidenced by certain GCS and FOUR scores. Further research should be focused on the comparison between the obtained GCS and FOUR score data and the anatomical substrate changes revealed by diagnostic tools such as head CT scans and brain fMRI. With these data, we could obtain the accurate subanatomical and clinical information needed to perform specific invasive therapy to lead to a far better outcome for patients.

\section{Conclusions}

The present study involved a comparison between the GCS and FOUR scores in TBI patients in out-of-hospital scenarios at different follow-up times. We introduced and compared different models for the prediction of morality outcome 24 hours after the injury and re-evaluated the predictive ability one and three months after the injury.

The results of our research confirm that there are no practical or clinical differences between the GCS and FOUR scores in terms of predicting morality outcomes 24 hours, one month, and three months after injury. Due to the different assessment categories, the FOUR score is more effective for evaluating patients who are unconscious and dependent on mechanical ventilation.

We believe that the FOUR score has promising predictive outcome potential and could be regularly performed in the prehospital setting, especially in intubated patients with brain injuries.

\section{Abbreviations}

FOUR - Full Outline of Unresponsiveness

GCS - Glasgow Coma Scale

TBI - Traumatic Brain Injury

ICU - Intensive Care Unit

ROC - Receiver Operating Characteristic 
IV - Intravenous Line

ET - Endotracheal Tube

ATLS - Advanced Trauma Life Support

CT - Computed Tomography

fMRI - functional Magnetic Resonance Imaging

GOS-E Glasgow Outcome Scale Extended

\section{Declarations}

\section{Ethics approval and consent to participate}

The present study was approved by the National Medical Ethics Committee of the Republic of Slovenia. We recruited only patients who gave signed consent to participate. Informed signed consent was obtained from the patients' or patient's guardian/caregivers.

\section{Consent for publication}

Informed signed consent was obtained, and explanations that data may be published in the study were provided.

\section{Availability of data and material}

The datasets collected and/or analysed during the current study are available from the corresponding author upon reasonable request.

\section{Competing interests}

The authors declare that they have no competing interests.

\section{Funding}

Not applicable

\section{Authors' contributions}

MRF contributed to the acquisition and interpretation of the data. MG performed the analysis of the data. JR revised the study. All authors read and approved the final manuscript.

\section{Acknowledgements}

Not applicable

\section{References}

1. Teasdale G, Jennett B. Assessment of coma and impaired consciousness. A practical scale. Lancet 1974;2(7872): 81-4. PubMed TheLancet ScienceDirect

2. Levy DE, Bates D, Caronna JJ, Cartlidge NE, Knill-Jones RP, Lapinski RH, Singer BH, Shaw DA, Plum F: Prognosis in nontraumatic coma. Ann Intern Med 1981; 94:293-301. PubMed ACP 
3. Jensen M, Neunzig HP, Emskotter T: Outcome prediction in comatose patients: significance of reflex eye movement analysis. J Neurol Neursurg Psychiatry 1987;50:389-92. PubMed

4. Starmark JE, Holmgren E, Stalhammar D: Current reporting of responsiveness in acute cerebral disorders: a survey of the neurosurgical literature. J Neurosurg 1988;69:692-8. JNS PubMed

5. Edgren E, Hedstrand U, Nordin M, Rydin E, Ronquist G: Prediction of outcome after cardiac arrest. Crit Care Med 1987;15:820-5. PubMed CCM

6. Jennett B, Teasdale G, Braakman R, Minderhoud J, Heiden J, Kurze T: Prognosis of patients with severe head injury. Neuro-surgery 1979;4:283-9. PubMed

7. Wijdicks EF, Bamlet WR, Maramattom BV, Manno EM, McClelland RL. Validation of a new coma scale: The FOUR score. Ann Neurol 2005;58(4): 585-93. PubMed

8. Sadaka F, Patel D, Lakshmanan R. The FOUR score predicts outcome in patients after traumatic brain injury. Neurocrit Care. 2012 Feb;16(1):95-101. doi: 10.1007/s12028-011-9617-5. PubMed

9. Iyer VN, Mandrekar JN, Danielson RD, Zubkov AY, Elmer JL, Wijdicks EF. Validity of the FOUR Score Coma Scale in the Medical Intensive Care Unit. Mayo Clin Proc. 2009;84(8):694-701. PubMed

10. Wijdicks EF, Kramer AA, Rohs T Jr, Hanna S, Sadaka F, O'Brien J, Bible S, Dickess SM, Foss M. Comparison of the Full Outline of UnResponsiveness score and the Glasgow Coma Scale in predicting mortality in critically ill patients. Crit Care Med. 2015;43(2):439-44. doi: 10.1097/CCM.0000000000000707. PubMed

11. Saika A, Bansal S, Mariamma P, Bhagavatula ID, Dhaval P. Shukla. Prognostic value of FOUR and GCS scores in determining mortality in patients with traumatic brain injury. Acta Neurochirurgica, The European Journal of Neurosurgery 2015;157(8):1323-28. Springer PubMed ResearchGate

12. Grmec Š, Gašparovic V. Comparison of APACHE II, MEES and Glasgow Coma Scale in patients with nontraumatic coma for prediction of mortality. Acute Physiology and Chronic Health Evaluation. Mainz Emergency Evaluation System. Crit Care. 2001;5(1):19-23. Epub 2000 Dec 14. PubMed SemanticScholar

13. Youden WJ. Index for rating diagnostic tests. Cancer 1950;3(1): 32-5. WileyOnlineLibrary

14. Hanley JA, McNeil BJ. The meaning and use of the area under a receiver operating characteristic (ROC) curve. Radiology 1982;143(1): 29-36. PubMed

15. McNeil BJ, Hanley JA. Statistical approaches to the analysis of receiver operating characteristic (ROC) curves. Med Decis Making 1984;4(2):137-50. ResearchGate

16. Hanley JA, McNeil BJ. A method of comparing the areas under receiver operating characteristic curves derived from the same cases. Radiology 1983;148(3):839-43. PubMed

17. Fawcett T. An introduction to ROC analysis. Pattern Recog Lett 2006;27:861-74. AcmDigitalLibrary

18. Murthy T. A new score to validate coma in emergency department-FOUR score. Ind J Neurotrauma 2009;6(1):59-62. ScienceDirect

19. Sharath S. Nair1, Anilkumar Surendran, Rajmohan B. Prabhakar, Meer M. Chisthi. Comparison between FOUR score and GCS in assessing patients with traumatic head injury: a tertiary centre study. Nair SS et al. Int Surg J. 2017 Feb;4(2):656662. IJS 
20. Yesim Serife BAYRAKTAR, Mert SAHINOGLU, Faruk CICEKCI, Inci KARA, Hakan KARABAGLI, Ates DUMAN, Jale Bengi CELIK. Comparison of Glasgow Coma Scale and Full Outline of Unresponsiveness (Four) Score: A Prospective Study. Turkish Neurosurgery 2019, 29 (2): 285-288 Read

21. Kishor Khanal, Sanjeeb Sudarshan Bhandari, Ninadini Shrestha, Subhash Prasad Acharya, and Moda Nath Marhatta. Comparison of outcome predictions by the Glasgow coma scale and the Full Outline of UnResponsiveness score in the neurological and neurosurgical patients in the Intensive Care Unit. Indian J Crit Care Med. 2016 Aug; 20(8): 473-476. Researchgate

22. Ching C. Foo, James J.M. Loan, and Paul M. Brennan. The Relationship of the FOUR Score to Patient Outcome: A Systematic Review. JOURNAL OF NEUROTRAUMA 36:2469-2483 (September 1, 2019) Mary Ann Liebert, Inc. DOI: 10.1089/neu.2018.6243 Mary Ann Liebert, Inc.

\section{Tables}

Table 1. Description of the FOUR score components

\begin{tabular}{|c|c|c|c|}
\hline Eye Response (E) & Motor Response (M) & Brainstem Reflexes (B) & Respiration (R) \\
\hline $\begin{array}{l}4 \text { Eyelids open or opened, tracking or } \\
\text { blinking to command }\end{array}$ & 4 Thumbs up, fist, or peace sign to command & $\begin{array}{l}4 \text { Pupil and corneal } \\
\text { reflexes present }\end{array}$ & $\begin{array}{l}4 \text { Not intubated, regular } \\
\text { breathing pattern }\end{array}$ \\
\hline 3 Eyelids open but not tracking & 3 Localizing to pain & 3 One pupil wide and fixed & $\begin{array}{l}3 \text { Not intubated, Cheyne-Stokes } \\
\text { breathing pattern }\end{array}$ \\
\hline $\begin{array}{l}2 \text { Eyelids closed, open to loud voice, not } \\
\text { tracking }\end{array}$ & 2 Flexion response to pain & $\begin{array}{l}2 \text { Pupil or corneal reflexes } \\
\text { absent }\end{array}$ & $\begin{array}{l}2 \text { Not intubated, irregular } \\
\text { breathing pattern }\end{array}$ \\
\hline $\begin{array}{l}1 \text { Eyelids closed, open to pain, not } \\
\text { tracking }\end{array}$ & 1 Extensor posturing & $\begin{array}{l}1 \text { Pupil and corneal } \\
\text { reflexes absent }\end{array}$ & 1 Breathes above ventilator rate \\
\hline 0 Eyelids remain closed with pain & $\begin{array}{l}0 \text { No response to pain or generalized } \\
\text { myoclonus status epilepticus }\end{array}$ & $\begin{array}{l}0 \text { Pupil, corneal, and cough } \\
\text { reflex absent }\end{array}$ & $\begin{array}{l}0 \text { Breathes at ventilator rate or } \\
\text { apnoea }\end{array}$ \\
\hline
\end{tabular}

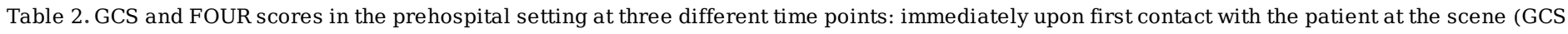

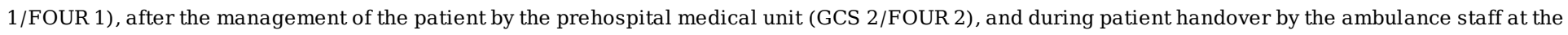
hospital (GCS 3/FOUR 3).

\begin{tabular}{ll}
\hline Time point & Variable \\
\hline Immediate first contact at the scene & GCS 1/FOUR 1 \\
After the management of the patient at the scene & GCS 2/FOUR 2 \\
Patient handover at the hospital & GCS 3/FOUR 3 \\
\hline
\end{tabular}

Table 3. Overview of the clinical characteristics of the cohort study.

\begin{tabular}{|c|c|c|c|c|c|c|c|}
\hline Severity & $\begin{array}{l}\text { Sex } \\
(M / F)\end{array}$ & $\begin{array}{l}\text { Age } \\
\text { (years } \pm S D)\end{array}$ & $\begin{array}{l}\text { FOUR Eye } \\
\text { Response } \\
\text { (median/min/max) }\end{array}$ & $\begin{array}{l}\text { FOUR Motor } \\
\text { Response } \\
(\text { median } / \mathrm{min} / \mathrm{max})\end{array}$ & $\begin{array}{l}\text { GCS Eye } \\
\text { Response } \\
\text { (median } / \min / \max \text { ) }\end{array}$ & $\begin{array}{l}\text { GCS Motor } \\
\text { Response } \\
(\operatorname{median} / \mathrm{min} / \mathrm{max})\end{array}$ & $\begin{array}{l}\text { GOS-E } \\
(\text { median/min/max) }\end{array}$ \\
\hline $\begin{array}{l}\text { Severe }^{a} \\
(\mathrm{~N}=35)\end{array}$ & $23 / 12$ & $59.0 \pm 24.7$ & $1 / 0 / 4$ & $3 / 0 / 4$ & $2 / 1 / 4$ & $4 / 1 / 6$ & $1 / 1 / 5$ \\
\hline $\begin{array}{l}\text { Moderate } b \\
(\mathrm{~N}=29)\end{array}$ & $24 / 5$ & $47.9 \pm 21.1$ & $3 / 0 / 4$ & $3 / 0 / 4$ & $3 / 1 / 4$ & $5 / 1 / 6$ & $3 / 1 / 5$ \\
\hline $\begin{array}{l}\text { Mild }^{\mathrm{C}} \\
(\mathrm{N}=121)\end{array}$ & $77 / 44$ & $51.8 \pm 24.1$ & $4 / 0 / 4$ & $4 / 0 / 4$ & $4 / 1 / 4$ & $6 / 1 / 6$ & $5 / 1 / 5$ \\
\hline $\begin{array}{l}\text { Other }{ }^{d} \\
(N=15)\end{array}$ & $9 / 6$ & $49.8 \pm 17.3$ & $4 / 0 / 4$ & $4 / 0 / 4$ & $4 / 1 / 4$ & $6 / 1 / 6$ & $5 / 1 / 5$ \\
\hline
\end{tabular}

${ }^{\text {a }}$ Head trauma - intracranial haemorrhage, brain oedema, severe loss of consciousness. 


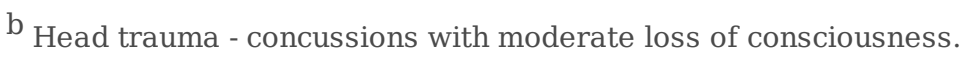

C Head trauma without brain damage.

d No head trauma.

$\mathrm{N}$ : number of patients by severity classification

Table 4. Scale metrics at 24 hours after injury.

\begin{tabular}{|c|c|c|c|c|c|c|}
\hline $\begin{array}{l}\text { Scale } \\
(\mathrm{N})\end{array}$ & $\begin{array}{l}\text { Best cut-off } \\
\text { point }\end{array}$ & $\begin{array}{l}\text { Sensitivity } \\
(\%)\end{array}$ & $\begin{array}{l}\text { Specificity } \\
(\%)\end{array}$ & $\begin{array}{l}\text { Correct prediction of outcome } \\
(\%)\end{array}$ & $\begin{array}{l}\text { Youden } \\
\text { index } \pm \text { SE }\end{array}$ & $\begin{array}{l}\text { ROC area } \pm \text { SE } \\
\quad \text { (CI95) }\end{array}$ \\
\hline $\begin{array}{l}\text { FOUR 1 } \\
(\mathrm{N}=200)\end{array}$ & 12 & 85 & 100 & 85 & $0.85 \pm 0.03$ & $\begin{array}{l}0.94 \pm 0.02 \\
(0.89- \\
0.99)\end{array}$ \\
\hline $\begin{array}{l}\text { GCS } 1 \\
(N=200)\end{array}$ & 8 & 88 & 100 & 88 & $0.88 \pm 0.02$ & $\begin{array}{l}0.93 \pm 0.02 \\
(0.89- \\
0.98)\end{array}$ \\
\hline
\end{tabular}

Table shows the best sensitivity, specificity, ROC area, and correct prediction of mortality outcome 24 hours after injury for the cut-off points in the FOUR and GCS models based on the best Youden index, 1: at immediate first contact at the scene. ROC: Receiver Operating Characteristic; FOUR: Full Outline of UnResponsiveness; GCS: Glasgow Coma Scale; N: number of patients enrolled in cohort study; SE: standard errors; SE (CI95): standard errors from 95\% confidence intervals.

Table 5. Scale metrics at 1 month after injury.

\begin{tabular}{|c|c|c|c|c|c|c|}
\hline $\begin{array}{l}\text { Scale } \\
(\mathrm{N})\end{array}$ & $\begin{array}{l}\text { Best cut-off } \\
\text { point }\end{array}$ & $\begin{array}{l}\text { Sensitivity } \\
(\%)\end{array}$ & $\begin{array}{l}\text { Specificity } \\
(\%)\end{array}$ & $\begin{array}{l}\text { Correct prediction of outcome } \\
(\%)\end{array}$ & $\begin{array}{l}\text { Youden } \\
\text { index } \pm S E\end{array}$ & $\begin{array}{l}\mathrm{ROC} \\
\text { area } \pm \mathrm{SE} \\
(\mathrm{CI} 95)\end{array}$ \\
\hline $\begin{array}{l}\text { FOUR } 2 \\
(\mathrm{~N}=200)\end{array}$ & 8 & 94 & 87 & 94 & $0.81 \pm 0.07$ & $\begin{array}{l}0.91 \pm 0.04 \\
(0.83-0.98)\end{array}$ \\
\hline $\begin{array}{l}\text { GCS } 3 \\
(\mathrm{~N}=200)\end{array}$ & 11 & 89 & 91 & 90 & $0.81 \pm 0.06$ & $\begin{array}{l}0.95 \pm 0.02 \\
(0.92-0.98)\end{array}$ \\
\hline $\begin{array}{l}\text { FOUR } 3 \\
(\mathrm{~N}=200)\end{array}$ & 8 & 94 & 87 & 94 & $0.81 \pm 0.07$ & $\begin{array}{l}0.91 \pm 0.04 \\
(0.83-0.98)\end{array}$ \\
\hline $\begin{array}{l}\text { GCS } 3 \\
(\mathrm{~N}=200)\end{array}$ & 11 & 89 & 91 & 90 & $0.81 \pm 0.06$ & $\begin{array}{l}0.95 \pm 0.02 \\
(0.92-0.98)\end{array}$ \\
\hline
\end{tabular}

Table shows the best sensitivity, specificity, ROC area, and correct prediction of mortality outcome 1 month after injury for the cutoff points in the FOUR and GCS models based on the best Youden index, 2: after initial management and intervention for the patient, 3: during the patient handover by ambulance staff at the hospital. ROC: Receiver Operating Characteristic; FOUR: Full Outline of UnResponsiveness; GCS: Glasgow Coma Scale; N: number of patients enrolled in cohort study; SE: standard errors; SE (CI95): standard errors from 95\% confidence intervals.

Table 6. Scale metrics at 3 months after injury. 


\begin{tabular}{|c|c|c|c|c|c|c|}
\hline $\begin{array}{l}\text { Scale } \\
(\mathrm{N})\end{array}$ & $\begin{array}{l}\text { Best cut-off } \\
\text { point }\end{array}$ & $\begin{array}{l}\text { Sensitivity } \\
(\%)\end{array}$ & $\begin{array}{l}\text { Specificity } \\
(\%)\end{array}$ & $\begin{array}{l}\text { Correct prediction of outcome } \\
(\%)\end{array}$ & $\begin{array}{l}\text { Youden } \\
\text { index } \pm \text { SE }\end{array}$ & $\begin{array}{l}\text { ROC } \\
\text { area } \pm \text { SE } \\
\text { (CI95) }\end{array}$ \\
\hline $\begin{array}{l}\text { FOUR 2 } \\
(\mathrm{N}=200)\end{array}$ & 12 & 93 & 84 & 92 & $0.77 \pm 0.08$ & $\begin{array}{l}0.89 \pm 0.04 \\
(0.81-0.97)\end{array}$ \\
\hline $\begin{array}{l}\text { GCS } 1 \\
(\mathrm{~N}=200)\end{array}$ & 12 & 86 & 92 & 87 & $0.78 \pm 0.06$ & $\begin{array}{l}0.93 \pm 0.02 \\
(0.90-0.97)\end{array}$ \\
\hline $\begin{array}{l}\text { FOUR } 3 \\
(\mathrm{~N}=200)\end{array}$ & 12 & 93 & 84 & 92 & $0.77 \pm 0.08$ & $\begin{array}{l}0.89 \pm 0.04 \\
(0.81-0.97)\end{array}$ \\
\hline $\begin{array}{l}\text { GCS } 1 \\
(\mathrm{~N}=200)\end{array}$ & 12 & 86 & 92 & 87 & $0.78 \pm 0.06$ & $\begin{array}{l}0.93 \pm 0.02 \\
(0.90-0.97)\end{array}$ \\
\hline $\begin{array}{l}\text { GCS } 1 \\
(\mathrm{~N}=200)\end{array}$ & 12 & 86 & 92 & 87 & $0.78 \pm 0.06$ & $\begin{array}{l}0.93 \pm 0.02 \\
(0.90-0.97)\end{array}$ \\
\hline $\begin{array}{l}\text { GCS } 2 \\
(\mathrm{~N}=200)\end{array}$ & 9 & 93 & 84 & 92 & $0.77 \pm 0.08$ & $\begin{array}{l}0.95 \pm 0.02 \\
(0.92-0.98)\end{array}$ \\
\hline
\end{tabular}

Table shows the best sensitivity, specificity, ROC area, and correct prediction of mortality outcome 3 months after injury for the cut-off points in the FOUR and GCS models based on the best Youden index, 1: at immediate first contact at the scene, 2: after initial management and intervention for the patient, 3: during the patient handover by ambulance staff at the hospital. ROC: Receiver Operating Characteristic; FOUR: Full Outline of UnResponsiveness; GCS: Glasgow Coma Scale; N: number of patients enrolled in cohort study; SE: standard errors; SE (CI95): standard errors from 95\% confidence intervals.

\section{Figures}
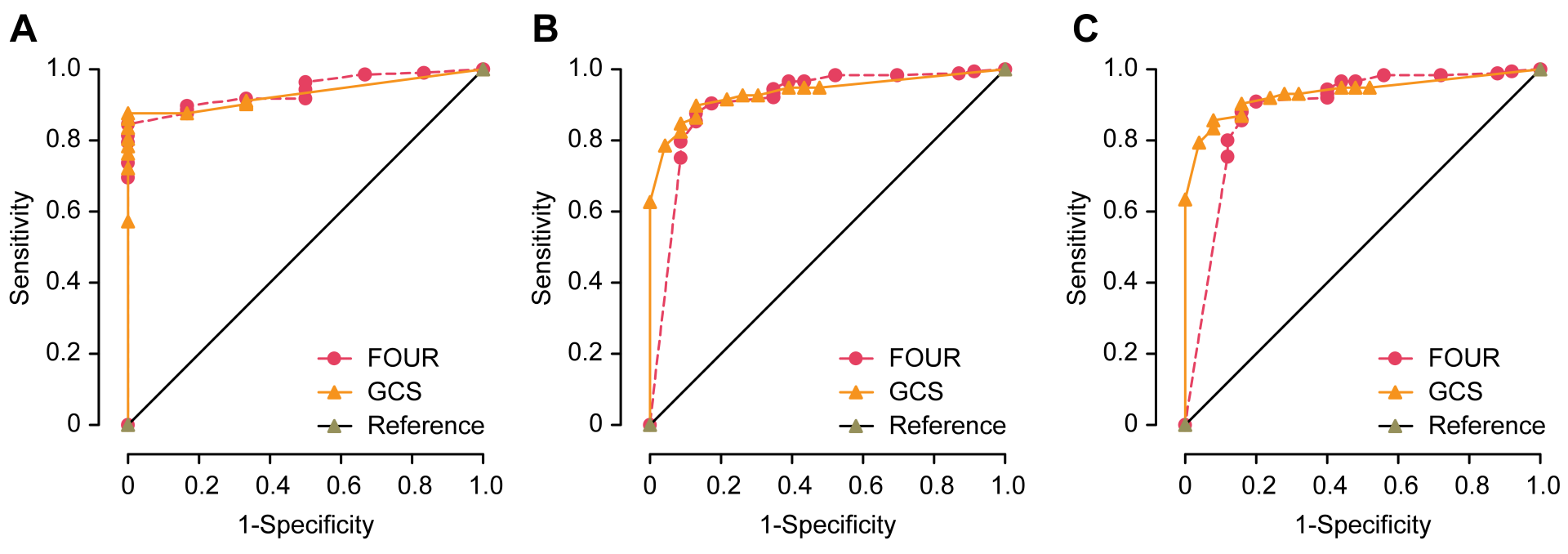

Figure 1

Comparative GCS and FOUR score outcome assessment in patients who survived 24 hours (A), one month (B) and three months (C) after the injury.

\section{Supplementary Files}

This is a list of supplementary files associated with this preprint. Click to download. 
- STROBEStatement.docx

Page $12 / 12$ 